\title{
Water Level measurement using COSMO-SkyMed Synthetic Aperture Radar
}

\author{
Filippo Biondi \\ University of L'Aquila
}

\author{
Angelica Tarpanelli \\ Consiglio Nazionale delle Ricerche
}

(CNR)

\author{
Pia Addabbo \\ Università degli studi \\ "Giustino Fortunato"
}

\author{
Carmine Clemente \\ University of Strathclyde
}

\author{
Danilo Orlando \\ Università degli Studi \\ "Niccolò Cusano"
}

\begin{abstract}
In this work, temporal series of Synthetic Aperture Radar (SAR) data are used to estimate water elevations. The proposed method is based on a Sub-Pixel Offset Tracking (technique) to retrieve the displacement of the double-bounce scattering effect of man made structures located in the proximity of the water surface. The experimental setup is focused on the cases of the Mosul dam in Iraq and the Missouri river in Kansas city. The proposed approach is applied to real data from the COSMO-SkyMed program. Results validated with in-situ and satellite radar altimeter measurements prove the effectiveness of the proposed method in measuring the water levels.
\end{abstract}

Index Terms-Synthetic Aperture Radar, COSMO-SkyMed, Water Elevation, Sub-Pixel Offset Tracking

\section{INTRODUCTION}

The flow of water in rivers and streams is of great interest because it represents the easiest access to water, considered to be a fundamental natural resource. The ability to quantify the flow of water in terms of river discharge and flow volume depends on the capability to monitor water surface height of water bodies. Even more important is to monitor the water level of dams which represent critical infrastructure for security with social, economic, and environmental implications. Unfortunately, a shared and worldwide database containing the historical and reliable data concerning water levels is not available and satellite remote sensing represents a valid observation tool to solve this lack of information.

In fact, in-situ gauges, installed along surface water bodies course, can be used to measure the water height and to describe its variation both in space and time; but the ground network is not globally and uniformly distributed, i.e., many rivers in developing countries are still unmonitored, and, since the 1980s, the decline of gauge stations, also in the developed countries, gets worse and worse the in-situ measurements availability [1]. For this reason, the advanced capability of satellite sensors to monitor inland water and the direct access to their data motivated scientists to integrate and reinforce the traditional monitoring of surface water with this new source of measurements. Thus, the satellite remote sensing may represent a valid observation tool to solve the lack of information as before explained, especially when different data sources are combined [2].
Nadir altimetry has been largely used in the past for measuring the river surface height from space $[3]-[\overline{8}]$. From the first studies carried out with Geosat [3] to the more recent analyses with Jason-2 and SARAL [8], [9], the improved capability of the altimeters allowed to monitor even narrow rivers, e.g. the Po river ( $\sim 300 \mathrm{~m}$ wide) or the Garonne River ( $\sim 200 \mathrm{~m}$ wide). Despite these encouraging results, the use of radar altimetry for narrow rivers is still limited because of uncertainty in the evaluation of the water surface elevation due to the local topography that contaminates the returned radar signal. With the synthetic aperture radar (SAR) technology applied to the altimeters, reliable measurements of water level are obtained for rivers of $200 \mathrm{~m}$ width [10] and according to the requirements of the next SWOT mission, rivers of $100 \mathrm{~m}$ width will be accurately observed by the new Karin sensors [11]. However, the nominal orbit of the satellites often does not guarantee the global coverage of all narrow rivers. The designed inter-track diamond distances and the revisit time represent obstacles to the monitoring of water courses. To overcome these issues, low cost satellite constellations are investigated in order to provide global coverage and finer temporal resolution. Moreover, the use of high resolution measurements is fundamental to ensure the level information of small water bodies. In literature, some examples show the use of SAR images to derive information of water level. For example, [12] showed the use of SAR images from ENVISAT and RADARSAT to indirectly estimate water level of the Severn River (UK) and the Red River (US).

On the other hand, the GNSS monitoring systems, combined with geotechnical, hydraulic and structural ones, could allow the monitoring of real-time dam displacements, with high accuracy, to ensure the correct functionality and the durability over time. Recent efforts in monitoring of dams using InSAR can be found in [13]-[15]. For a whole understanding of the dam's infrastructure deformation it is worth to study the relation between water levels and displacements. In this context, InSAR measurements allow possible continuous investigation of water levels over a wide area that includes the entire reservoir as well as the surrounding area, offering a clear picture of the dynamics of deformations. 


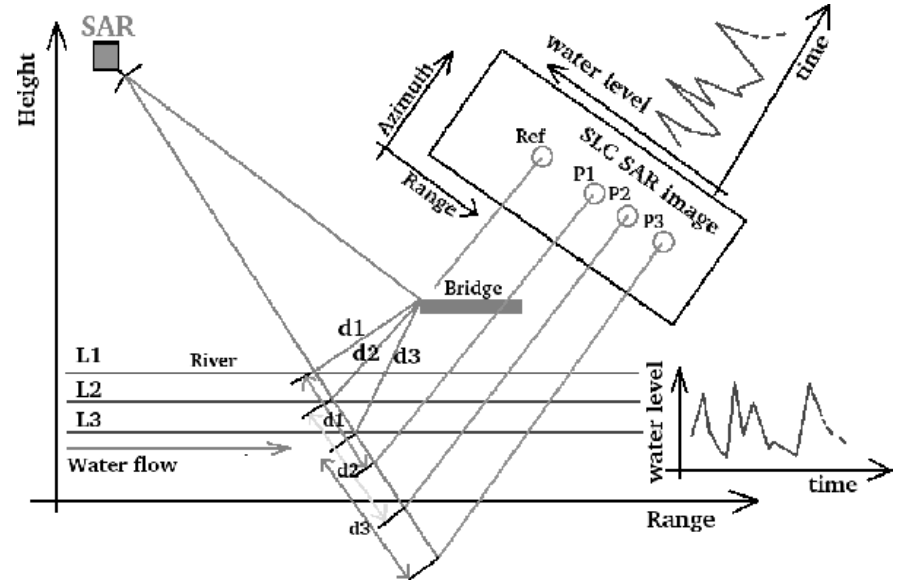

Fig. 1. The observation geometry.

The main objective of this work is to contribute in solving the information-gap problem of water levels monitoring, for rivers or dam's reservoirs, through a SAR signal processing technique. Particularly, a pixel tracking technique, proposed in [16] and based on the localized spectral analysis, is here used with the objective to track in time the water level temporal variations. To achieve water level measurements, the proposed method exploits the measurement of the distance between bridges or other man-made objects on the embankments. The height estimation is obtained by measuring the cross-slantrange distance between the edge of the structure and the echo of second bounce reflected by the water surface. This physical phenomenon is tracked in time allowing observations of the trend of water level variations. The two analysed case studies prove the effectiveness of the method in estimating water levels both over dams and rivers.

The remainder of this paper is organized as follows. In Section III. the proposed methodology is presented, whereas in Section IIII the performance of the proposed method are assessed. Finally, in Section IV] the conclusions are drawn.

\section{THE PROPOSED METHODOLOGY}

In this section, the proposed methodology is described. The geometry of the observation is depicted in Figure 11. The essential element for the estimation is represented by a manmade structure, a bridge in Figure 1 located in the proximity of the water surface (i.e., the river). The correspondence between the height-range coordinates and the azimuth range is also shown in the figure. Without loss of generality the water is supposed to flow along the range direction from left to right. A reference point, indicated in figure as "Ref" represents the focused single-bounce backscattered echo, which is constituted by the front-edge of the bridge that is visible on the SAR image. Its position is supposed constant during the entire time series measurements. The positions of points P1, P2 and $\mathrm{P} 3$ on the projection screen, represent the double-bounce backscattered echoes of the same target. The distance of the two-way propagation system depends on the heights of the water levels L1, L2 and L3, which are variable and depending on the time.

The architecture of the whole proposed estimation technique is depicted in Figure 2. Input data consist in a long temporal series of InSAR measurements and the processing scheme is composed by four processing blocks. The co-registration stage is performed at first. After co-registration, the second step exploits the range shifts for an initial coarse estimation of the double-bounce shifts and error correction. To extract range shifts, the offset components of the sub-pixel normalized cross-correlation is considered, which, according to [17], is given by

$$
\begin{aligned}
D_{\text {tot }}^{i}= & D^{i}{ }_{\text {displ }}+D_{\text {topo }}^{i}+D^{i}{ }_{\text {orbit }}+D_{\text {control }}^{i}+D_{\text {atmo }}^{i} \\
& +D^{i}{ }_{\text {noise }}, i=1, \ldots, G,
\end{aligned}
$$

for each interferometric complex pair, indexed by $i$ and belonging to a time series of length $G$. The offset terms comprises $D^{i}$ that is the component generated by the variation of the water level and detected as a sub-pixel misalignment existing between the first SAR image (master) and the slave SAR image. $D_{\text {topo }}^{i}$ is the offset component generated by the earth displacement when located on highly sloped terrain, $D_{\text {orbit }}^{i}$ is the offset caused by residual errors of the satellite orbits, $D_{\text {control }}^{i}$ is the offset component generated by general attitude and control errors of the flying satellite trajectory, $D_{\text {atmo }}^{i}$ and $D_{\text {noise }}^{i}$ are the contributions accounting for change in the atmospheric and ionospheric dielectric constant and for decorrelation phenomena (spatial, temporal, thermal, etc.), respectively. After the compensation of the different offset terms, the displacement component can be isolated.

The region of interest (ROI) extraction is, then, performed by the third block and the last step consists in range shifts and water level estimation.

The interested reader can refer to [16] for further details about the estimation procedure.

\section{Performance Analysis}

The procedure is tested processing two long temporal series of CSK data. The processed data belongs to the COSMOSkyMed mission, conceived by ASI (Agenzia Spaziale Italiana), and funded by the Italian Ministry of Research and the Italian Ministry of Defense, Italy. For the analysis, a long temporal dataset of CSK images are considered based on two case studies whose locations are shown in Figure 3 superimposed to the optical images over the two areas of interest: the Mosul dam in Iraq (on the left) and the Missouri river in Kansas city (on the right).

The specifications of the datasets used for study areas are reported in Table II. The number of images varies from 83 images for the study area at Kansas City and 113 for Mosul, and, the temporal interval of the images is different, ranging from about 6 to 8 years, respectively.

The water levels estimated by the proposed method are validated by comparison with the supposed ground-truths 


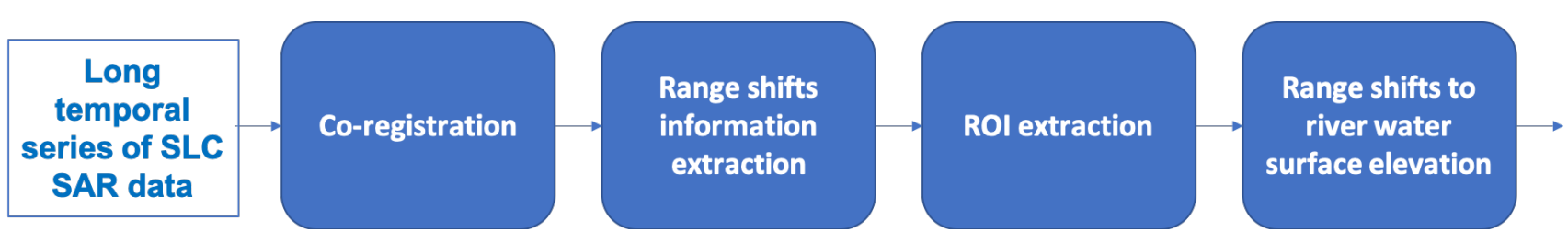

Fig. 2. The block-scheme of the proposed procedure.
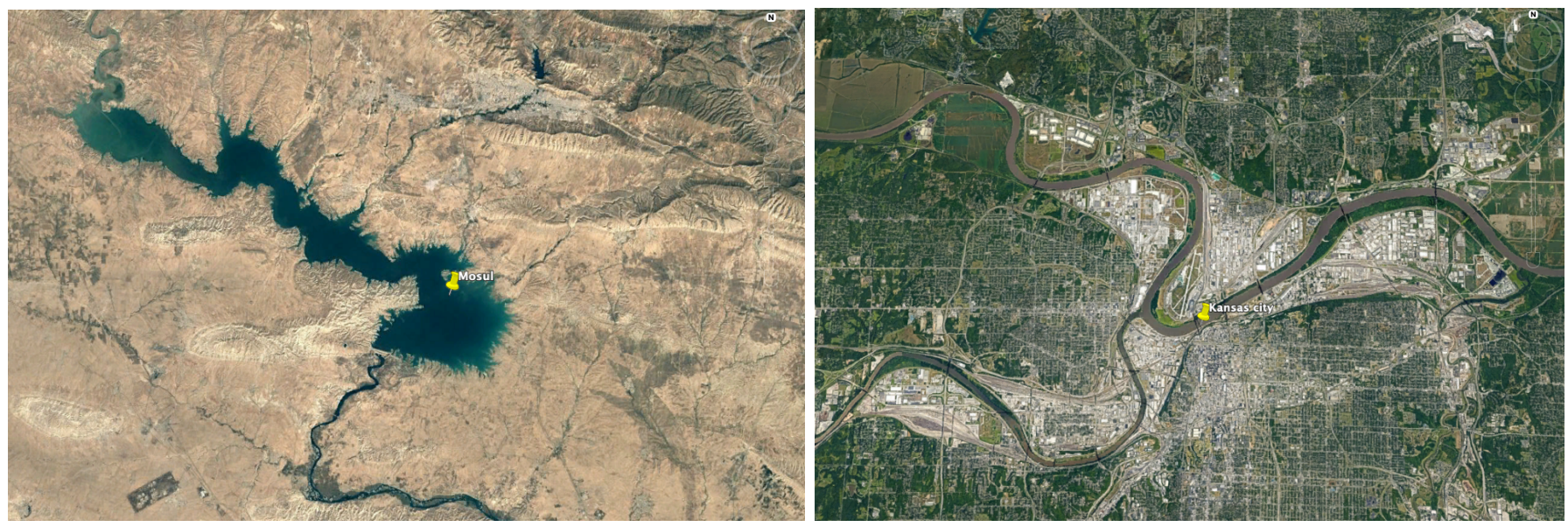

Fig. 3. Optical images of the analysed case studies: the Mosul dam in Iraq (on the left) and the Missouri river at Kansas city (on the right).

TABLE I

SATELLITE DATASETS USED IN THE ANALYSIS AND CORRESPONDING GROUND TRUTHS

\begin{tabular}{|c|c|c|c|c|}
\hline Location & Ground truth & COORDINATES (WGS-84) & $\begin{array}{l}\text { Time of obs. } \\
\text { [yyyy/mm/dd] }\end{array}$ & $\begin{array}{l}\text { Images } \\
\text { number }\end{array}$ \\
\hline Kansas City & USGS & $39^{\circ} 6^{\prime} 42.20^{\prime \prime} \mathrm{N}, 94^{\circ} 35^{\prime} 17.30^{\prime \prime} \mathrm{W}$ & $2012 / 12 / 31-2019 / 03 / 30$ & 83 \\
\hline Mosul & Hydroweb & $36^{\circ} 40^{\prime} 49.67^{\prime \prime} \mathrm{N}, 42^{\circ} 54^{\prime} 6.36^{\prime \prime} \mathrm{E}$ & 2011/06/07 - 2019/09/09 & 133 \\
\hline
\end{tabular}

TABLE II

PERFORMANCE INDICATORS

\begin{tabular}{cccc}
\hline \hline Location & R & NS & RMSE [m] \\
\hline Mosul & 0.97 & 0.93 & 1.71 \\
Kansas City & 0.96 & 0.93 & 0.67 \\
\hline \hline
\end{tabular}

available over the study areas during a consistent period with respect to the CSK orbits. Specifically, for the Missouri river at Kansas city, the water levels ground-truths are provided by the United States Geological Survey (USGS) dataset [18]. For the Mosul dam, because of the lack of the in-situ data, water levels from satellite radar altimetry, derived by Hydroweb dataset [19], are supposed as ground-truth in this case.

The trend of the estimated water levels are depicted in Figure 4. The blue lines represent the water-levels measured by using the proposed approach on CSK data $\left(W_{i}^{\text {obs }}\right)$ and the red ones are the supposed ground-truths $\left(W_{i}^{\text {truth }}\right)$.

In Figure 5, the scatterplots are reported for both case studies representing the comparison between the water levels estimated using CSK and the supposed ground truths. For both cases, a good agreement is found because the scatter points lie in the proximity of the linear regression represented by the red line in the figure. This is confirmed by the performance parameters (reported in Table III):

- the Pearson correlation coefficient (R)

$$
R=\frac{\sum_{i=1}^{N}\left(W_{i}^{o b s}-\mu_{o b s}\right)\left(W_{i}^{\text {truth }}-\mu_{\text {truth }}\right)}{\sqrt{\sum_{i=1}^{N}\left(W_{i}^{o b s}-\mu_{o b s}\right)^{2}} \sqrt{\sum_{i=1}^{N}\left(W_{i}^{\text {truth }}-\mu_{\text {truth }}\right)^{2}}}
$$

with

$$
\mu_{o b s}=\frac{1}{N} \sum_{i=1}^{N} W_{i}^{o b s}
$$

and

$$
\mu_{\text {truth }}=\frac{1}{N} \sum_{i=1}^{N} W_{i}^{\text {truth }}
$$



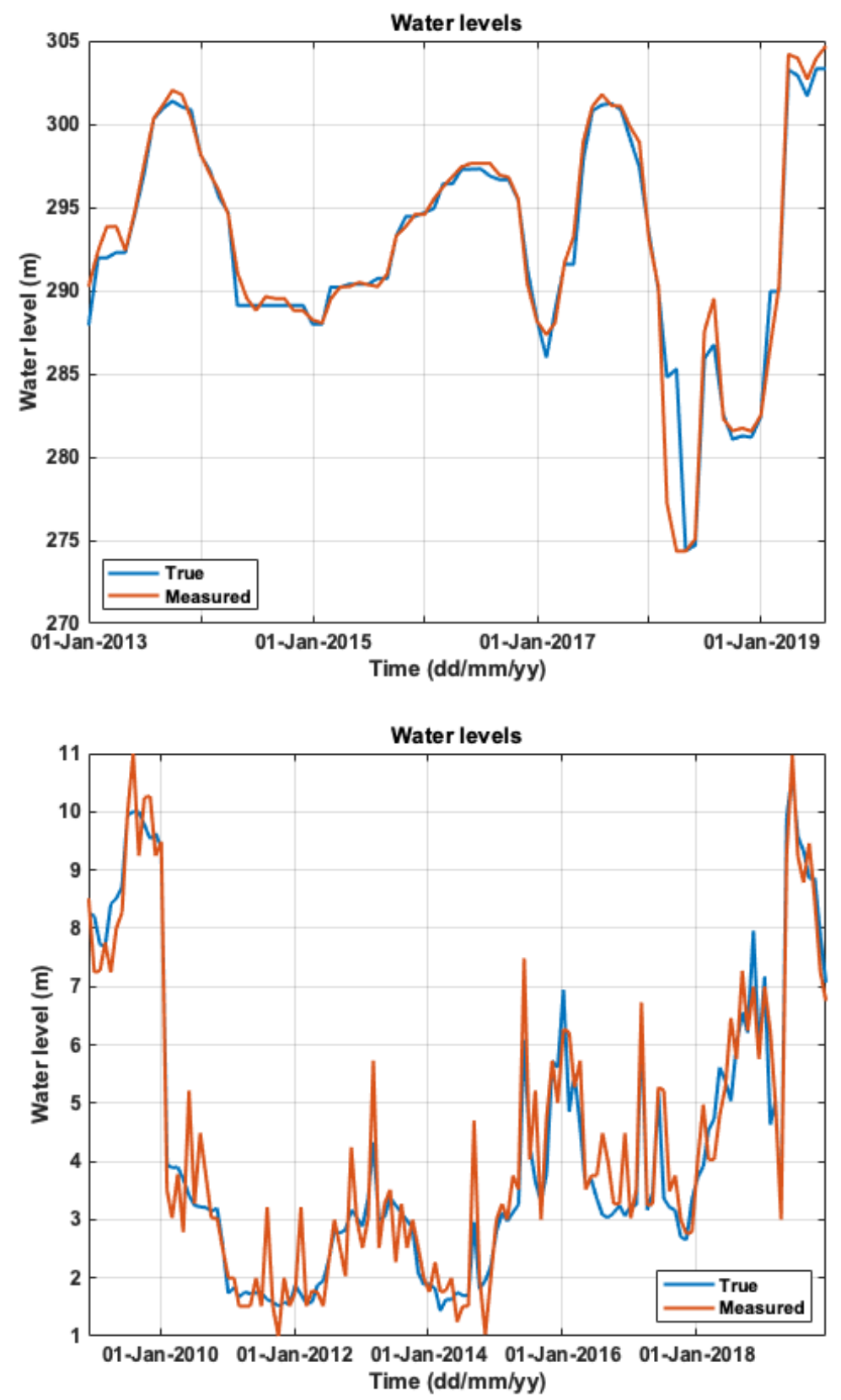

Fig. 4. Water levels for the analysed case studies: the Mosul dam in Iraq (on the top) and the Missouri river at Kansas city (on the bottom). Red lines are the retrieved values of water levels whereas the blue lines represents the ground-truths.

- the Nash-Sutcliffe efficiency (NS) [20]

$$
N S=1-\frac{\sum_{i=1}^{N}\left(W_{i}^{\text {obs }}-W_{i}^{\text {truth }}\right)^{2}}{\sum_{i=1}^{N}\left(W_{i}^{\text {obs }}-\mu_{o b s}\right)^{2}},
$$

- the root-mean square error (RMSE)

$$
R M S E=\sqrt{\frac{1}{N} \sum_{1}^{N}\left(W_{i}^{\text {obs }}-W_{i}^{\text {truth }}\right)} .
$$

\section{CONCLusions And Final Remarks}

This research demostrated that the information-gap problem of river flow monitoring could be solved through water flow elevation estimation with a synthetic aperture radar (SAR) signal processing technique.

This paper proposed the application of a robust technique for tracking the double-bounce reflections of some reference structure crossing the water surface and to measure the gap space existing between the water surface and the structure. Specifically, the difference in position between the single and 

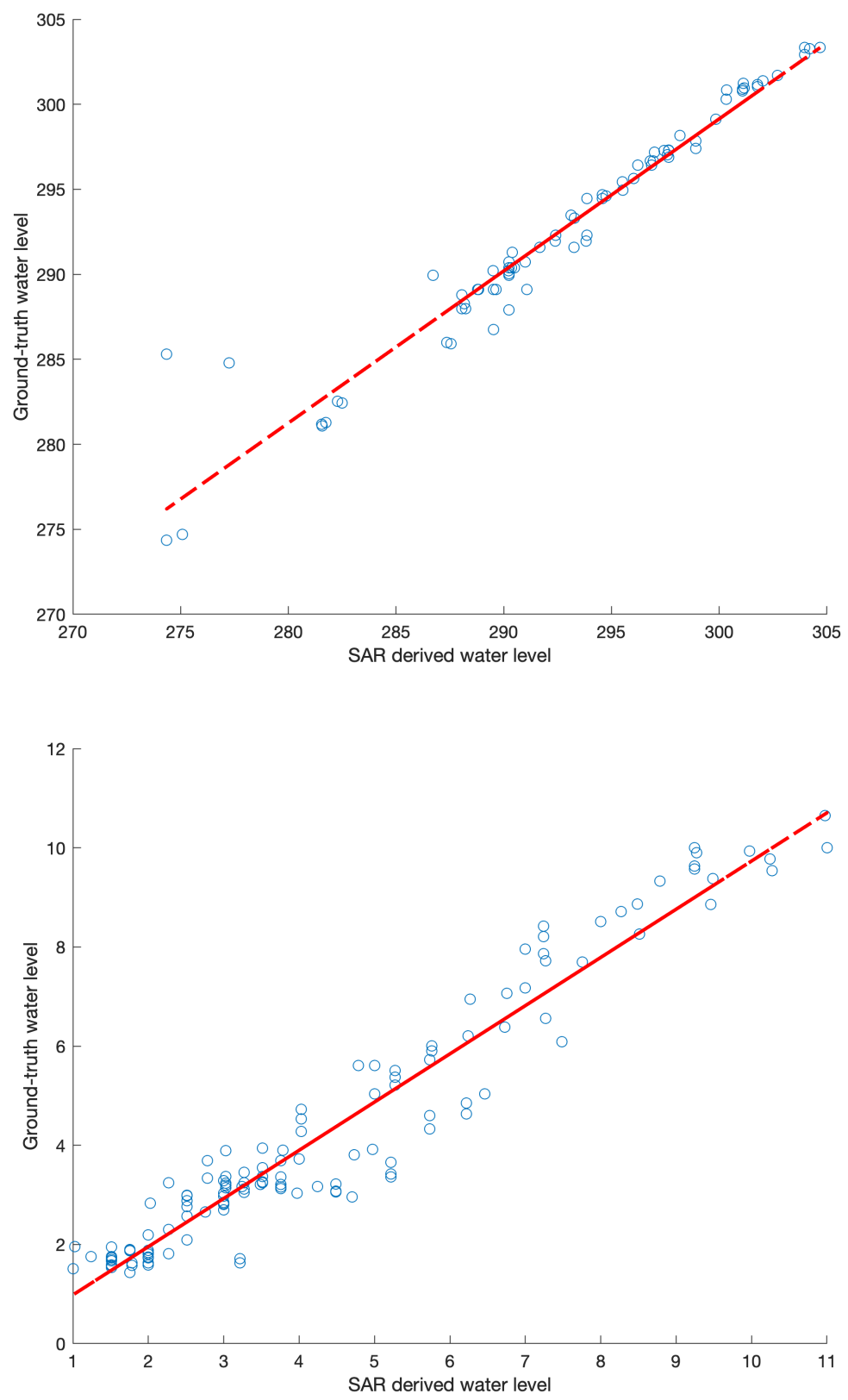

Fig. 5. Scatterplots of the estimated water levels and the ground-truths' measurements: the Mosul dam in Iraq (on the top) and the Missouri river at Kansas city (on the bottom).

double bounce is suitably measured over the time.

The experiments have been evaluated processing real data consisting of a long temporal series of COSMO-SkyMed data. Two case studies are analysed in this paper: the Mosul dam in Iraq and the Missouri river at Kansas city.

Finally, the high correlation between the estimated CSK results and the ground-truths confirms the effectiveness of the proposed method in both the case studies.

\section{REFERENCES}

[1] D. M. Hannah, S. Demuth, H. A. J. van Lanen, U. Looser, C. Prudhomme, G. Rees, K. Stahl, and L. M. Tallaksen, "Large-scale river flow archives: importance, current status and future needs," Hydrol Process., vol. 25, no. 7, pp. 1191-1200, March 2011.

[2] P. Addabbo, M. Focareta, S. Marcuccio, C. Votto, and S. Ullo, "Land cover classification and monitoring through multisensor image and data combination," vol. 2016-November, 2016, pp. 902-905, cited By 7. [Online]. Available: https://www.scopus.com/inward/record.uri? eid=2-s2.0-85007483026\&doi=10.1109\%2fIGARSS.2016.7729228\& partnerID=40\&md5=62b2e14678b9aae0d65f6640a8226671

[3] C. J. Koblinsky, R. T. Clarke, A. C. Brenner, and H. Frey, "Measurement of River Level Variations with Satellite Altimetry," Water Resour. Res., vol. 29, no. 6, pp. 1839-1848, 1993. 
[4] A. V. Kouraev, E. A. Zakharova, O. Samain, N. M. Mognard, and A. Cazenave, "Ob river discharge from TOPEX/Poseidon satellite altimetry (1992-2002)," Remote Sens. Environ., vol. 93, pp. 238-245, 2004.

[5] J. G. Leon, S. Calmant, F. Seyler, M. P. Bonnet, M. Cauhope, F. Frappart, N. Filizola, and P. Fraizy, "Rating curves and estimation of average water depth at the upper Negro River based on satellite altimeter data and modeled discharges," J. Hydrol., vol. 328, pp. 481-496, 2006.

[6] A. Tarpanelli, S. Barbetta, L. Brocca, and T. Moramarco, "River discharge estimation by using altimetry data and simplified flood routing modeling," Remote Sens., vol. 5, no. 9, pp. 4145-4162, 2013.

[7] A. Domeneghetti, A. Tarpanelli, L. Brocca, S. Barbetta, T. Moramarco, A. Castellarin, and A. Brath, "The use of remote sensing-derived water surface data for hydraulic model calibration," Remote Sens. Environ., vol. 149, pp. 130-141, 2014.

[8] S. Biancamaria, F. Frappart, A. S. Leleu, V. Marieu, D. Blumstein, J. D. Desjonquères, F. Boy, A. Sottolichio, and A. Valle-Levinson, "Satellite radar altimetry water elevations performance over a $200 \mathrm{~m}$ wide river: Evaluation over the Garonne River,' Adv. Space Res., vol. 59, no. 1, pp. 128-146, 2016.

[9] C. Normandin, F. Frappart, A. T. Diepkilé, V. Marieu, E. Mougin, F. Blarel, B. Lubac, B. N., and B. A., "Evolution of the Performances of Radar Altimetry Missions from ERS-2 to Sentinel-3A over the Inner Niger Delta," Remote Sens., vol. 10, no. 6, p. 833, 2018.

[10] R. Schneider, A. Tarpanelli, K. Nielsen, H. Madsen, and P. BauerGottwein, "Evaluation of multi-mode Cryosat-2 altimetry data over the Po River against in situ data and a hydrodynamic model," Adv. Water Resour, vol. 112, pp. 17-26, 2018.

[11] L. L. Fu, D. Alsdorf, E. Rodríguez, R. Morrow, N. Mognard, J. Lambin, P. Vaze, and T. Lafon, "The SWOT (Surface Water and Ocean Topography) Mission: Spaceborne Radar Interferometry for Oceanographic and Hydrological Applications," Proceedings of OceanObs'09: Sustained Ocean Observations and Information for Society (Vol. 2), Venice, Italy, 21-25 September 2009. Hall, J., Harrison, D.E. \& Stammer, D., Eds., ESA Publication WPP-306.

[12] P. Matgen, G. Schumann, J. B. Henry, L. Hoffmann, and L. Pfister, "Integration of SAR-derived river inundation areas, high-precision topo- graphic data and a river flow model toward near real-time management," Int. J. Appl. Earth Obs. Geoinf., vol. 9, pp. 247-263, 2007.

[13] A. Anghel, G. Vasile, R. Cacoveanu, C. Ioana, S. Ciochina, and J. Ovarlez, "Scattering centers detection and tracking in refocused spaceborne sar images for infrastructure monitoring," IEEE Transactions on Geoscience and Remote Sensing, vol. 53, no. 8, pp. 4379-4393, Aug 2015.

[14] S. L. Ullo, P. Addabbo, D. Di Martire, S. Sica, N. Fiscante, L. Cicala, and C. V. Angelino, "Application of DInSAR Technique to High Coherence Sentinel-1 Images for Dam Monitoring and Result Validation Through In Situ Measurements," IEEE Journal of Selected Topics in Applied Earth Observations and Remote Sensing, vol. 12, no. 3, pp. 875-890.

[15] A. Anghel, G. Vasile, C. Ioana, R. Cacoveanu, and S. Ciochina, "Micro-doppler reconstruction in spaceborne sar images using azimuth time-frequency tracking of the phase history," IEEE Geoscience and Remote Sensing Letters, vol. 13, no. 4, pp. 604-608, April 2016.

[16] F. Biondi, A. Tarpanelli, P. Addabbo, C. Clemente, and D. Orlando, "Pixel tracking to estimate rivers water flow elevation using cosmoskymed synthetic aperture radar data," Remote Sensing, vol. 11, no. 21, 2019. [Online]. Available: https://www.mdpi.com/2072-4292/ $11 / 21 / 2574$

[17] D. O. Nitti, R. F. Hanssen, A. Refice, F. Bovenga, and R. Nutricato, "Impact of DEM-assisted coregistration on high-resolution SAR interferometry,", IEEE Transactions on Geoscience and Remote Sensing, vol. 49, no. 3, pp. 1127-1143, 2011.

[18] "USGS Water Data for the Nation." [Online]. Available: https: //waterdata.usgs.gov/

[19] J.-F. Crétaux, W. Jelinski, S. Calmant, A. Kouraev, V. Vuglinski, M. Bergé-Nguyen, M.-C. Gennero, F. Nino, R. A. D. Rio, A. Cazenave, and P. Maisongrande, "SOLS: A lake database to monitor in the Near Real Time water level and storage variations from remote sensing data," Advances in Space Research, vol. 47, no. 9, pp. 1497 - 1507, 2011. [Online]. Available: http://www.sciencedirect.com/science/article/pii/S0273117711000287

[20] J. Nash and J. Sutcliffe, "River flow forecasting through conceptual models part I - A discussion of principles," Journal of Hydrology, vol. 10, no. 3, pp. 282 - 290, 1970. [Online]. Available: http://www.sciencedirect.com/science/article/pii/0022169470902556 